\title{
Treatment of pneumatosis cystoides coli by oxygen inhalation
}

\author{
A. E. MACKINNON, J. D. FRANK, * AND P. MORRIS \\ From the Royal Manchester Children's Hospital, Pendlebury, Manchester
}

SUMMARY Endotracheal intubation and intermittent positive pressure ventilation were used to overcome the difficulties of oxygen therapy for pneumatosis cystoides coli in a 9-year-old child with Down's syndrome and a congenital heart defect. As compared to previously reported cases, a shorter duration of treatment and a lower arterial oxygen tension proved successful.

It has been known for a long time that cystic collections of gas may occur in the bowel wall of both animals and man. The first description of the condition is attributed to du Vernoi in 1730, and John Hunter described the first case in England (Koss, 1952; Kenney, 1963). In adults the gas is present in cysts measuring up to a few centimetres in diameter lying beneath either the mucosa or serosa. The condition is known as pneumatosis cystoides intestinalis or coli depending on the extent of disease process. It may be idiopathic (Koss, 1952) or associated with other diseases including pulmonary disease (Botsford and Krakower, 1938; Doub and Shea, 1960), pyloric stenosis (Dhall et al., 1968), malignant conditions (Finney, 1908; Dale and Pearse, 1950; Williams $e t$ al., 1963; Thorpe, 1965), collagen diseases (Meihoff et al., 1968, White et al., 1970; Mueller et al., 1972), adhesions from previous surgery (Koss, 1952), and occurs after long-term administration of practolol (Thein and Asquith, 1977).

Most reports of gas within the bowel wall of children are different as the gas is present as small bubbles or linear collections (Stone et al., 1968). These are now recognized to be examples of necrotizing enterocolitis that occur mainly in the newborn (Bell ct al., 1971), though a similar appearance may be found in other conditions (Robinson et al., 1974). It is suggested that the term enteropneumatosis be used to describe these collections of gas.

Four cases of pneumatosis cystoides coli have been previously recorded in children. 2 cases were in girls aged 13 and 16 years after abdominal surgery (Koss, 1952) and 2 were associated with dermatomyositis (Mueller et al., 1972; Oliveros et al., 1973).

\section{Case report}

A girl was born in 1966 at term, weighing $2 \cdot 8 \mathrm{~kg}$, and

Received 4 May 1977

*Present address: The Hospital for Sick Children, Great Ormond Street, London. with the clinical features of Down's syndrome. Chromosome analysis gave 47 chromosomes with trisomy in the 21-group. At 6 months an atrioventricular canal defect was diagnosed associated with pulmonary hypertension and a small left-toright shunt. She remained reasonably well until aged 7 when she was started on digoxin on account of increasing cyanotic attacks.

At the age of 9 she presented with a 2-month history of colicky abdominal pain, loose stools with mucus and blood, and continual soiling. A polypoid mass was found on rectal examination. On sigmoidoscopy numerous gas-filled cysts were seen; several of these were biopsied and deflated with a 'pop'. Histology of these biopsy specimens showed a giant-cell reaction in the submucosa. A plain $x$-ray of the abdomen and barium enema showed that cysts were present from the mid-transverse colon to the rectum (Figs. 1, 2) confirming the diagnosis of pneumatosis cystoides coli.

In spite of symptomatic treatment as an outpatient her symptoms became more severe and she was refused attendance at school because of persistent soiling. She was therefore readmitted to hospital for definitive treatment. $X$-ray showed the cysts to be present as before, and it was decided to use oxygen therapy as originally described by Forgacs $e t$ al. (1973). This was attempted initially using an oxygen tent and a face mask but neither was tolerated by the child in spite of sedation. It was decided to follow a colonoscopy with oxygen therapy using intermittent positive pressure ventilation (IPPV) via an endotracheal tube for 24 hours. Anaesthesia was induced with IV-thiopentone followed by pancuronium bromide and insertion of a plastic nasoendotracheal tuke. Anaesthesia was maintained using a halothaneoxygen mixture with manual IPPV.

Colonoscopy confirmed the presence of cysts to within $5 \mathrm{~cm}$ of the anal verge (Fig. 3). The child was admitted to the intensive care unit and IPPV continued with $100 \% \mathrm{O}_{2}$ using an Engstrom ventilator 


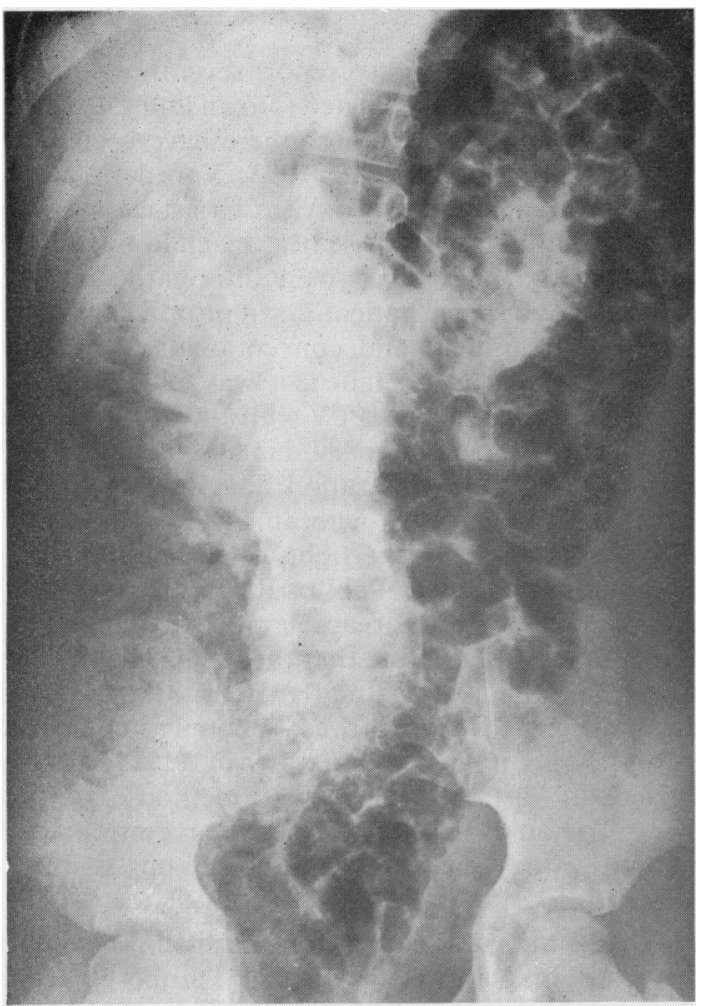

Fig. 1 X-ray of abdomen before treatment.

set to maintain normocarbia. Control of ventilation was facilitated with intermittent doses of phenoperidine and diazepam as required. Full monitoring was carried out including blood gas analysis, initially 3hourly. The $\mathrm{PaO}_{2}$ attained with an $\mathrm{F}_{\mathrm{r}} \mathrm{O}_{2} \mathbf{1 . 0}$ was between 208 and $237 \mathrm{mmHg}(27 \cdot 7-31.6 \mathrm{kPa}) .24$ hours later colonoscopy showed that the cysts had deflated. The child was extubated and the postintubation period was uneventful. Her symptoms settled immediately and she has remained well for over 6 months with normal bowel actions and no soiling. Plain $x$-rays of the abdomen 24 hours and 10 weeks after treatment were normal (Fig. 4). She has returned to school and leads an active life.

\section{Discussion}

The aetiology of the cysts in pneumatosis cystoides is not known. The association with other gastrointestinal diseases, particularly obstructive lesions, has led to the suggestion that gas from the lumen of the bowel is forced through the damaged mucosa (Koss, 1952). Coincidental pulmonary disease indicates that the gas may pass through the mediastinum

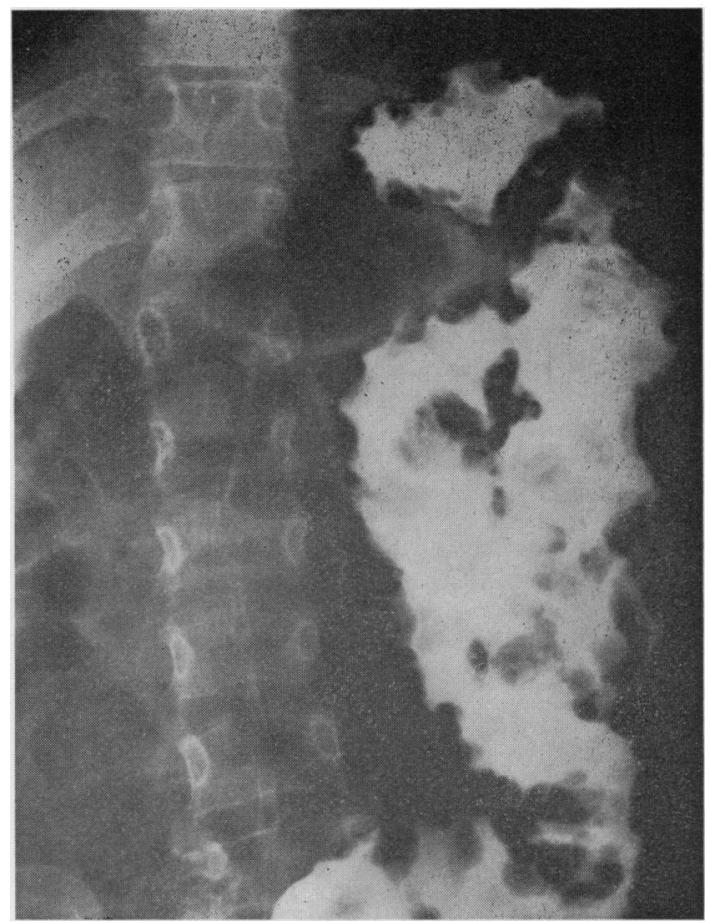

Fig. 2 Barium enema before treatment.

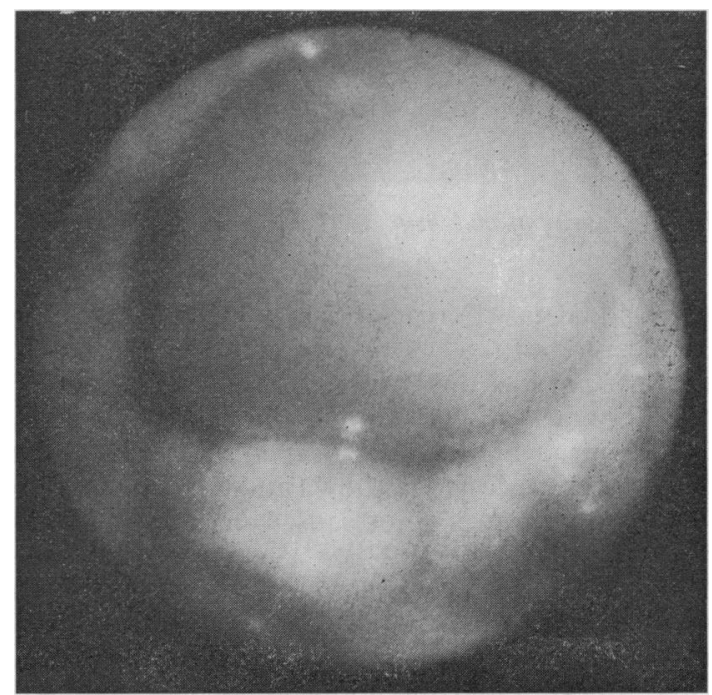

Fig. 3 Colonoscopic appearance of cysts.

to the bowel mesentery, and support for this theory has come from animal experiments (Keyting et al., 1961). However, this does not explain the formation of submucosal gas cysts whose contents are related 


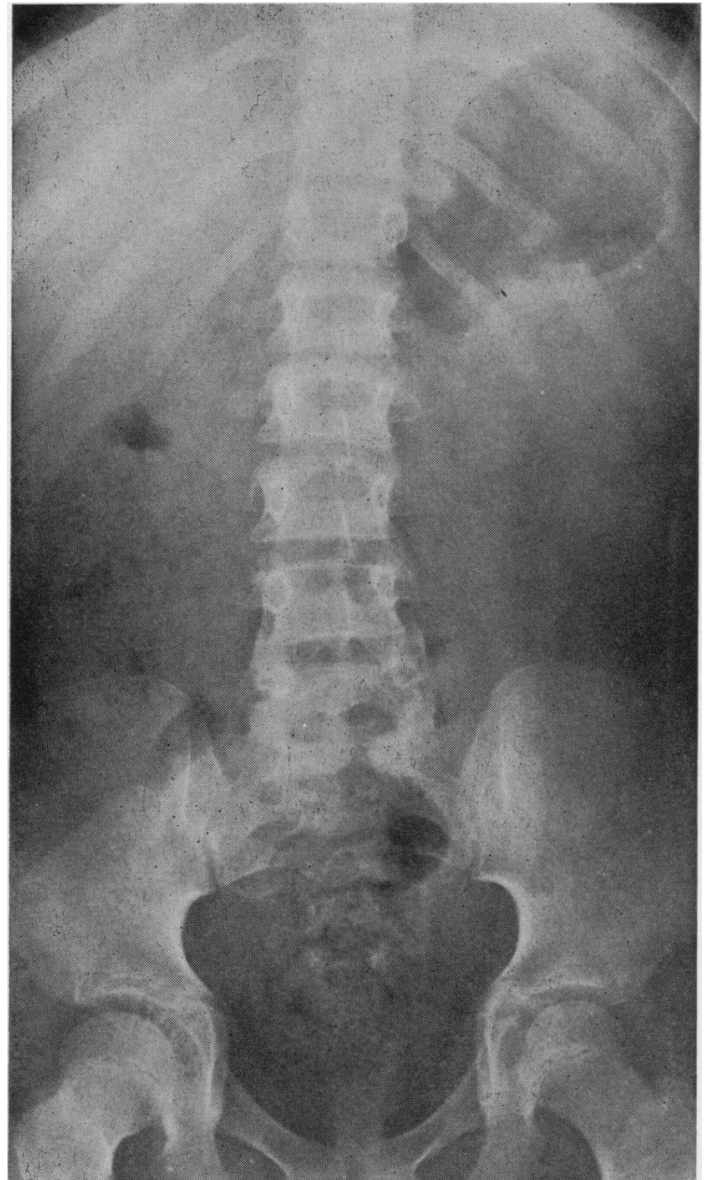

Fig. 4 X-ray of abdomen 10 weeks after treatment.

to intestinal gas (Forgacs et al., 1973). Studies of the composition of the gas have shown it to be variable and have not shed any light on the aetiology (Kenney, 1963; Forgacs et al., 1973). It is unlikely that anaerobic organisms are involved in the production of the cysts as was suggested by Down and Castleden (1975) since perforation has not caused peritonitis in this condition (Koss, 1952).

Until recently the management of the condition was unsatisfactory. Some cases have undergone spontaneous resolution (Doub and Shea, 1960; Navani, 1966; Moore, 1968) and in others resection has been followed by recurrence (Sames, 1964). Forgacs et al. (1973) predicted that by breathing a high concentration of oxygen the total tension of gases at the venous end of the capillaries would be lowered, thereby increasing the rate of diffusion of gas from the cysts (Nunn, 1969). As the cysts deflate they reach a criti- cal diameter at which they will collapse (La Place relationship).

Since Forgacs's original report several other cases have been successfully treated (Down and Castleden, 1975; Watson, 1976), though there have been some recurrences (Forgacs et al., 1973; Van der Linden, 1974). Administration of oxygen by a face mask or oxygen tent in an otherwise healthy child is difficult, particularly if the child is mentally retarded. When the severity of this patient's symptoms demanded definitive treatment, and conventional methods of oxygen administration failed, it was felt that endotracheal intubation and IPPV with $100 \%$ oxygen was justified. In man pulmonary damage due to a high inspired oxygen concentration does not develop in less than 24 hours even with an $\mathrm{F}_{\mathrm{I}} \mathrm{O}_{2}$ of 1.0 (Leigh, 1975). In this patient the right-to-left shunt made it impossible to achieve a $\mathrm{PaO}_{2}$ of $300 \mathrm{mmHg}(400 \mathrm{kPa})$ as recommended by Forgacs et al. (1973).

It is interesting to note that the cysts deflated with a maximum $\mathrm{PaO}_{2}$ of $237 \mathrm{mmHg}(31.6 \mathrm{kPa})$ and that the duration of treatment was 24 hours as compared to the 6 days used by Forgacs et al. (1973) and by Down and Castleden (1975). This method of oxygen therapy should be considered when conventional methods of oxygen administration are impossible.

We thank Mr. S. J. Cohen for permission to report this case and Professor L. A. Turnberg, Hope Hospital, University of Manchester School of Medicine, for carrying out the colonoscopy.

\section{References}

Bell, R. S., Graham, C. B., and Stevenson, J. K. (1971). Roentgenologic and clinical manifestations of neonatal necrotizing enterocolitis. American Journal of Roentgenology, Radium Therapy, and Nuclear Medicine, 112, 123-134.

Botsford, T. W., and Krakower, C. (1938). Pneumatosis of the intestine in infancy. Journal of Pediatrics, 13, 185-194.

Dale, W. A., and Pearse, H. E. (1950). Gas cysts of the intestines. Surgery, Gynecology and Obstetrics, 90, 215-220.

Dhall, D. P., Mahaffy, R. G., and Matheson, N. A. (1968). Intestinal pneumatosis treated by pyloroplasty. Journal of the Royal College of Surgeons of Edinburgh, 13, 226-229.

Doub, H. P., and Shea, J. J. (1960). Pneumatosis cystoides intestinalis. Journal of the American Medical Association, 172, 1238-1242.

Down, R. H. L., and Castleden, W. M. (1975). Oxygen therapy for pneumatosis coli. British Medical Journal, 1, 493-494.

Finney, J. M. T. (1908). Gas cysts of the intestine. Journal of the American Medical Association, 51, 1291-1298.

Forgacs, P., Wright, P. H., and Wyatt, A. P. (1973). Treatment of intestinal gas cysts by oxygen breathing. Lancet, 1, 579-582.

Kenney, J. G. (1963). Pneumatosis intestinalis. Clinical Radiology, 14, 70-76.

Keyting, W. S., McCarver, R. R., Kovarik, J. L., and Daywitt, A. L. (1961). Pneumatosis intestinalis: a new concept. Radiology, 76, 733-741. 
Koss, L. G. (1952). Abdominal gas cysts. Archives of Pathology, 53, 523-549.

Leigh, J. M. (1975). Post-operative oxygen administration. British Journal of Anaesthesia, 47, 108-112.

Meihoff, W. E., Hirschfield, J. S., and Kern, F. (1968). Small intestinal scleroderma with malabsorption and pneumatosis cystoides intestinalis. Journal of the American Medical Association, 204, 854-858.

Moore, H. D. (1968). Diagnosis and natural history of gas cysts of the colon. British Medical Journal, 2, 536-537.

Mueller, C. F., Morehead, R., Alter, A. J., and Michener, W. (1972). Pneumatosis intestinalis in collagen disorders. American Journal of Roentgenology, Radium Therapy, and Nuclear Medicine, 115, 300-305.

Navani, S. V. (1966). Pneumatosis intestinalis: spontaneous clinical and radiological resolution. Postgraduate Medical Journal, 42, 659-660.

Nunn, J. F. (1969). Applied Respiratory Physiology, 1st ed., p. 366. Butterworth, London.

Oliveros, M. A., Herbst, J. J., Lester, P. D., and Ziter, F. A. (1973). Pneumatosis intestinalis in childhood dermatomyositis. Pediatrics, 52, 711-712.

Robinson, A. E., Grossman, H., and Brumley, G. W. (1974). Pneumatosis intestinalis in the neonate. American Journal of Roentgenology, Radium Therapy, and Nuclear Medicine, 120, 333-341.
Sames, C. P. (1964). Pneumatosis cystoides intestinalis. Proceedings of the Royal Society of Medicine, 57, 400.

Stone, H. H., Allen, W. B., Smith, R. B., and Haynes, C. D. (1968). Infantile pneumatosis intestinalis. Journal of Surgical Research, 8, 301-307.

Thein, S. L., and Asquith, P. (1977). Pneumatosis coli: complication of practolol. British Medical Journal, 1, 268.

Thorpe, G. J. (1965). Pneumatosis cystoides intestinalis associated with abdominal carcinomatosis. Postgraduate Medical Journal, 41, 41-42.

Van der Linden, W. (1974). Reappearance of intestinal gas cysts after oxygen treatment. Lancet, 2, 1388-1389.

Watson, R. D. S. (1976). Successful treatment of pneumatosis coli with oxygen. British Medical Journal, 1, 199.

White, W. D., Treece, T. R., and Juniper, K. (1970). Pneumatosis in scleroderma of the small bowel. Journal of the American Medical Association, 212, 1068.

Williams, M. J., Sutherland, D. H., and Clark, C. G. (1963). Lymphosarcoma of the small intestine with a malabsorption syndrome and pneumatosis intestinalis. Gastroenterology, 45, 550-557.

Correspondence to Mr. A. E. Mackinnon, Royal Manchester Children's Hospital, Pendlebury, Manchester M27 1HA.

The following articles will appear in future issues of this journal:

The practice of infant feeding among Asian immigrants. S. K. M. Jivani.

Fetal growth in different racial groups. J. Alvear and $O$. G. Brooke.

Long-term study of smoking by secondary schoolchildren. M. H. Banks, B. R. Bewley, J. M. Bland, J. R. Dean, and $V$. Pollard.

Motor nerve conduction velocities in Leigh's encephalomyelopathy. A. Moosa.

Echovirus encephalitis and myositis in primary immunoglobulin deficiency. A. D. B. Webster, J. H. Tripp, A. R. Hayward, A. D. Dayan, R. Doshi, E. H. MacIntyre, and D. A. J. Tyrrell.

Psychological determinants of infantile pyloric stenosis. Susan Revill and J. A. Dodge.

Establishing demand feeding in hospital. P. Cruse, P. Yudkin, and J. D. Baum.

Oxidative metabolism in cord-blood polymorphonuclear leucocytes. R. G. Strauss and M. J. Seifert. 